\title{
BCCIN4.
}

\section{DIFFERENT METHODS OF THREE-POINT BENDING ANALYSIS OF POLYMER EPOXY REINFORCED WITH FIBERGLASS LAMINATED FACES.}

\author{
$\underline{\text { João Pedro Monteiro Cheloni }}^{(1)}$, Marcio Eduardo Silveira ${ }^{(1)}$, Leandro Jose da Silva ${ }^{(2)}$
}

(1) Applied Numerical Simulation Laboratory, Federal University of São João Del Rei-UFSJ, Mechanical Engineering Department, São João Del Rei, MG, Brazil

(2) Center of Technological Innovation in Composite Materials, Federal University of São João

Del Rei-UFSJ, Mechanical Engineering Department, São João Del Rei, MG, Brazil

https://doi.org/10.21452/bccm4.2018.16.03

\begin{abstract}
The purpose of this paper is the study of mechanical behavior in three-point bending of polymer epoxy using different amount of glass fibers laminated faces as reinforcement. Therefore, it was used experimental method, numerical simulation using linear and non-linear method and analytical method of composite beams analysing force, displacement and normal stress. The specimens were prepared using hand lay-up process and vacuum bag compaction. It was realized tensile and flexural tests in the specimens obtaining mechanical properties used in numerical simulation and analytical method. The numerical simulation was performed using linear and non-linear method with 3D solid elements. The materials were considered isotropic. The results showed similar values between methods with emphasis for the non-linear simulation that most approached the experimental results.
\end{abstract}

\section{INTRODUCTION}

Composite materials comprise from polymers reinforced with fibers, structural concretes, others that use ceramic and metal materials [1,2]. The polymer composites may exhibit excellent properties due to use great possibility of fibers combinations and orientations, forming optimized and specific structures for different types of loading [3]. The basic characteristic of a composite is to combine at macroscopic level, at least two distinct phases called matrix and reinforcement [4].

The use of glass fibers as reinforcements in laminated composites provide advantages like great cost/benefit ratio between the reinforcements offered for manufacturing polymer composites. Commonly glass fibers are used in applications that require some increase in strength because its 
properties as high weight-strength ratio, high tensile strength and low cost. However, there are some limitation in this material for example, short fatigue life and temperature sensitivity, mainly comparing with carbon fibers [5,6]

Nowadays, fiberglass laminates are being used at the top and bottom (as faces) of some types of materials, as well as in sandwich structures, to improve resistance under flexural loads [7-9]. There are some methods for bending analysis of composite materials that help understand the behavior and identify values of the stresses which the material is subjected. One of the most commonly used methods is numerical simulation by finite elements $[10,11]$.

In this paper, it is shown the three-point static bending behavior of epoxy resin reinforced with different amount of glass fibers laminated using four different methods, experimental procedure, linear and non-linear numerical simulation and analytical method of composite beams. The loads, displacement and stress were obtained by methods and a comparison was made among them.

\section{MATERIALS AND METHODS}

To accomplish the study, three different materials with the same thickness were analysed. It was performed specimens of polymer epoxy, specimens of polymer epoxy reinforced with 3 layers of fibers glass laminated at the top and bottom (PE3L) and specimens of polymer epoxy reinforced with 5 layers of fibers glass laminated at the top and bottom (PE5L). The conception of materials used is shown in Figure 1.

The polymer epoxy used in this paper was Renlan M with hardener HY 951 provided by Huntsman-Brazil. The material used as reinforcement was plain weave glass fibers cloth $\left(200 \mathrm{~g} / \mathrm{m}^{2}\right.$ ) supplied by Owens Corning-Brazil.

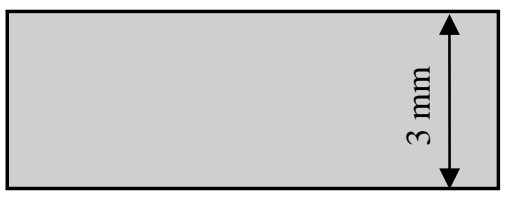

(a)

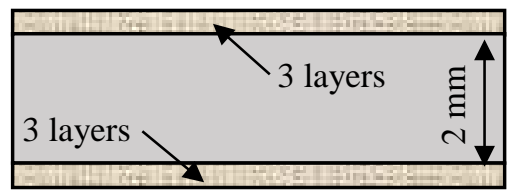

(b)

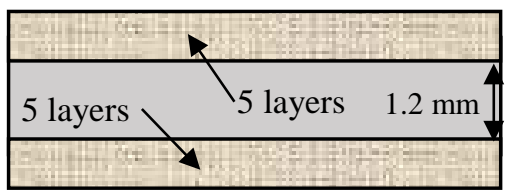

(c)

Figure 1: Sample illustration: (a) polymer epoxy, (b) PE3L and (c) PE5L

\subsection{Manufacturing of specimens}

Firstly, both laminates used as reinforcement of polymer epoxy were performed, one of them using three layers and the other using five layers. These laminated were created by manual lamination manufacturing (hand lay-up) which the epoxy resin mixed with hardener (10:1 ratio), was homogeneous spread over each layer obtaining volumetric fraction $40 \%$ fibers. Soon after, the vacuum bag lamination process was performed, to provide better resin compaction and distribution. The cure process occurred at room temperature, $25^{\circ} \mathrm{C}$. After seven days curing, a part of the laminate was separated to obtain at least five specimens for mechanical tests and the other part to use as face reinforcement of polymer epoxy. Using specific molds for each material to obtain the same total thickness, the specimens of polymer epoxy with and without glass fibers laminated faces were formed. 


\subsection{Tensile and Flexural tests}

The uniaxial tensile tests were performed in each material individually using Universal Mechanical Test Machine SHIMADZU AG-X Plus. It was created, five specimens of glass fibers laminated according to ASTM D3039 ${ }^{23}$ Standard [12]. It was used cross-head speed 2 mm.min ${ }^{-1}$ with room temperature $25^{\circ} \mathrm{C}$. It was created five specimens of polymer epoxy were analyzed according to ASTM D638 ${ }^{24}$ Standard [13]. The three-point bending test was performed according BS EN 2562 ${ }^{25}$ Standard [14] for polymer epoxy with and without glass fibers laminates faces. It was used the Universal Mechanical Test Machine SHIMADZU AG-X Plus at cross-head speed 2 $\mathrm{mm}_{\mathrm{min}}{ }^{-1}$. Five specimens for each material were analyzed with dimensions: $100 \mathrm{~mm}$ length, 10 $\mathrm{mm}$ width and $3 \mathrm{~mm}$ total thickness.

\subsection{Numerical Simulation}

Finite Elements Model was used to analyse the behavior of three types of specimens in this paper during bending tests. It was realized two types of simulation, using linear static solution and dynamic non-linear solutions.

The numerical simulations were performed using 3D solid elements. The linear methods were performed for three-point bending with constrain located below the specimen not allowing $\mathrm{z}$ axis movement. The simulation was accomplished resorting to the OptStruct Solver and a displacement of $2 \mathrm{~mm}$ was applied in the center through rigid elements, used to distribute the load along section. Non-linear simulation methods were carried out using Radioss Solver. It was created contact surface between laminated faces and cylindrical support surface using coefficient of friction 0.3. A displacement of $2 \mathrm{~mm}$ was applied in the central support. All rollers (fixed and mobile) were considered rigid (non-deformable).

In all simulations, both cross-ply glass fibers laminated and polymer epoxy were considered isotropic. The Figure 2 shows the discretization of the specimens made by finite elements. The Figure 3(a) shows the linear model with rigid elements used and Figure 3(b) shows the non-linear model with cylindrical support surfaces.

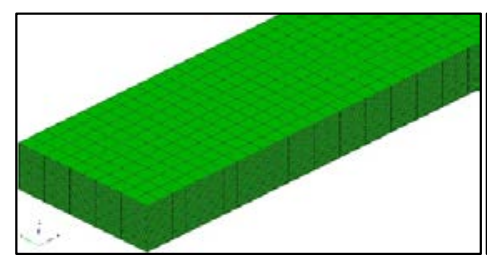

(a)

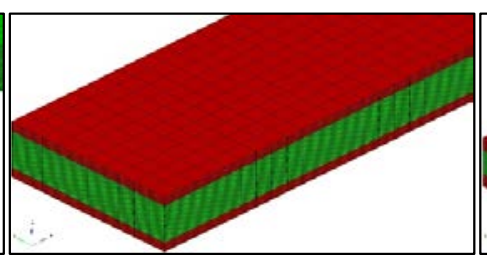

(b)

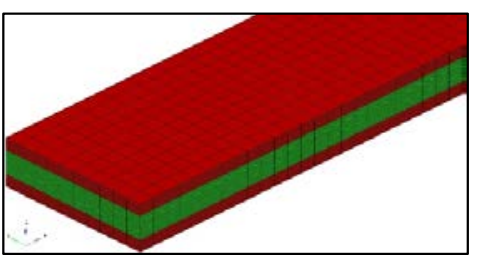

(c)

Figure 2: Discretization by finite elements of (a) polymer epoxy, (b) PE3L and (c) PE5L

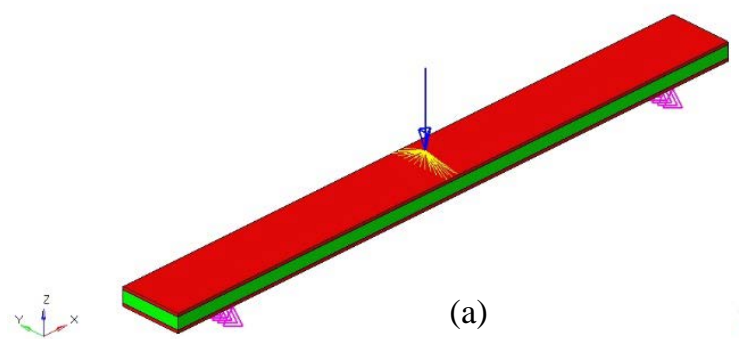

Figure 3: (a) Rigid elements and constrains used in linear simulation and (b) cylindrical support surface used in non-linear simulation 


\subsection{Analytical method of composite beams}

The analytical method performed in this study were based on the theory of composite beams. Since the polymer epoxy reinforced with laminated glass fibers faces is not homogeneous materials, it is necessary to modify the cross section of the beam into a section made of a single material. Therefore, the flexural stress can be given as:

$$
\sigma_{f}=n \frac{M c}{I} \quad \text { with } \quad n=\frac{E_{1}}{E_{2}}
$$

where $M$ is the bending moment, $c$ is the perpendicular distance of the neutral axis, $I$ is the transformed moment of inertia, $E_{1}$ is the Elasticity Modulus of material 1 and $E_{2}$ is the Elasticity Modulus of material 2. During the three-point bending loading the maximum deflection $\delta$ can be estimated by:

$$
\delta=\frac{F L^{3}}{48 E I}
$$

where $F$ is the force and $L$ is the span distance.

\section{RESULTS AND DISCUSSION}

\subsection{Mechanical properties - tensile and flexural tests}

The mechanical properties related to tensile tests of polymer epoxy and glass fibers laminated, as well as the mechanical properties related to flexural tests of PE3L and PE5L are shown in Table 1.

Table 1: Mechanical properties of tensile and flexural tests

\begin{tabular}{ccccc}
\hline \multirow{2}{*}{ Materials } & \multicolumn{2}{c}{ Tensile } & \multicolumn{2}{c}{ Flexural } \\
\cline { 2 - 5 } & Strength[MPa] & Modulus[GPa] & Strength[MPa] & $\begin{array}{c}\text { Equivalent } \\
\text { Modulus[GPa] }\end{array}$ \\
\hline Laminates & $329.15 \pm 30.07$ & $16.14 \pm 2.09$ & - & - \\
Epoxy & $19.08 \pm 2.02$ & $1.60 \pm 0.20$ & $18.45 \pm 1.55$ & - \\
PE3L & - & - & $292.76 \pm 5.30$ & $12.70 \pm 1.10$ \\
PE5L & - & - & $293.43 \pm 5.80$ & $17.14 \pm 0.83$ \\
\hline
\end{tabular}

The Elasticity Modulus using 5 layers as reinforcement is higher 34,96 \% when compared using 3 layers. It can be seen from the flexural strength analyses that equivalent moment of inertia of the polymer epoxy reinforced with 5 layers is largest, but the moment generated by the force during the test is also largest, which makes the maximum flexural strength, equivalent in both materials using the method of composite beams. 
Some failure modes were observed in the specimens during the flexural tests. The polymer epoxy without reinforcement, presented a fragile and sudden fracture. However, as shown in the Figure 4 (a) and (b), the polymer epoxy using 3 and 5 layers as reinforcement presented, due to compression on the top face, some broken fibers. Another failure occured was delamination between the faces and polymer epoxy.

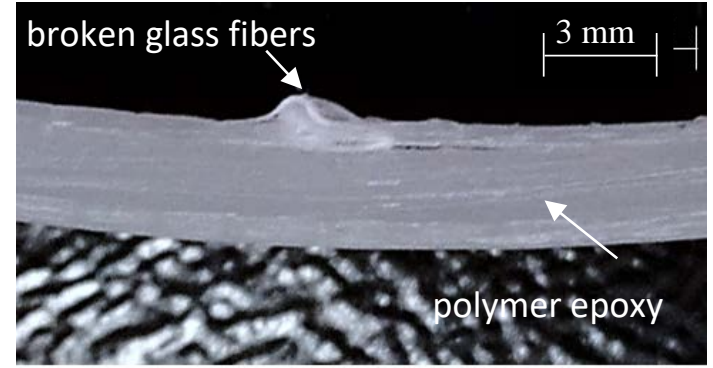

(a)

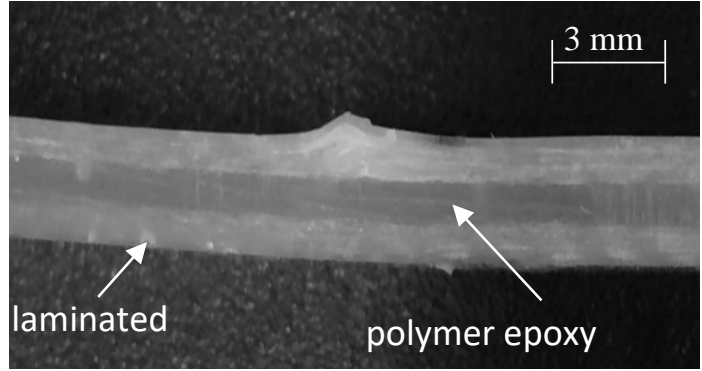

(b)

Figure 4 : Failure modes in the polyer epoxy reinforced with (a) 3 and (b) 5 layers of glass fiber laminated

\subsection{Numerical Simulation}

The specimens behavior in the linear and non-linear simulation of flexural tests are shown in Figure 5. It is noticed that in the linear simulations the values of the compression stresses were affected by the rigid elements, due to the impossibility of displacements imposed by type of elements.
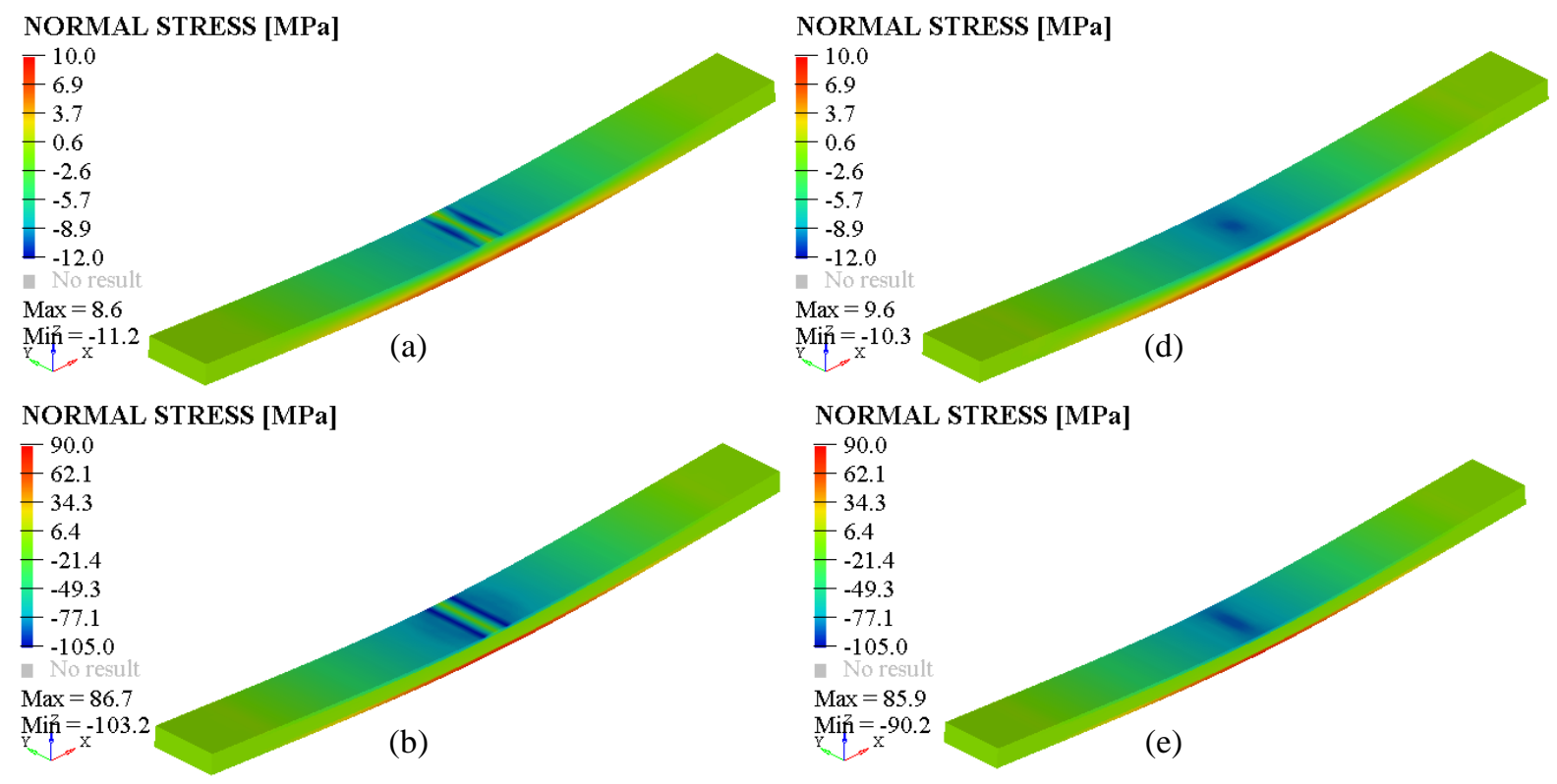

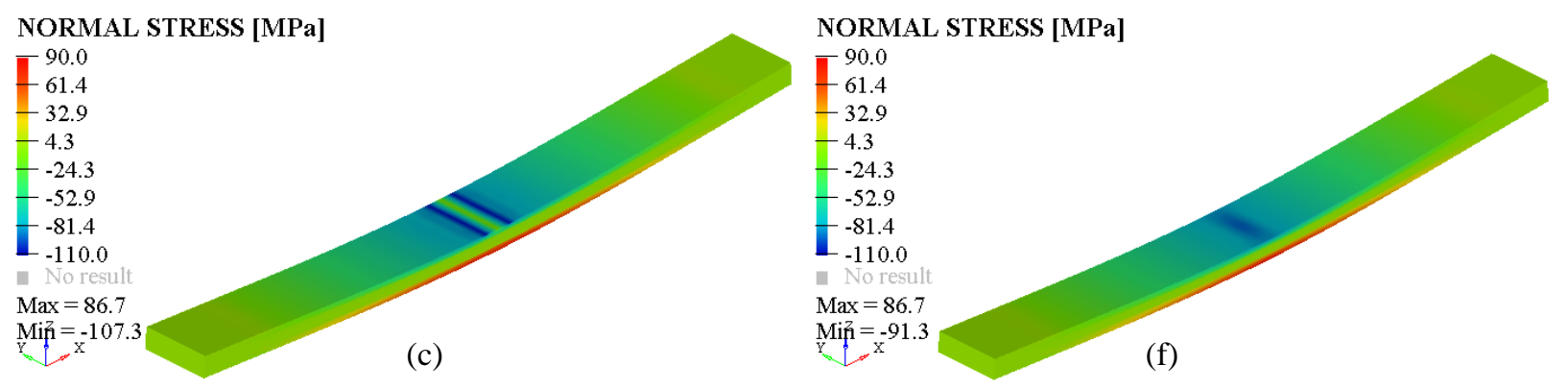

Figure 5: Linear simulation results of (a) polymer epoxy (b) PE3L and (c) PE5L. Non-linear simulation results of (d) polymer epoxy (e) PE3L and (f) PE5L.

The Figure 6 shows load $\mathrm{x}$ displacement diagram among non-linear simulation and experimental methods. Through this analysis it can be observed similar values between the methods.

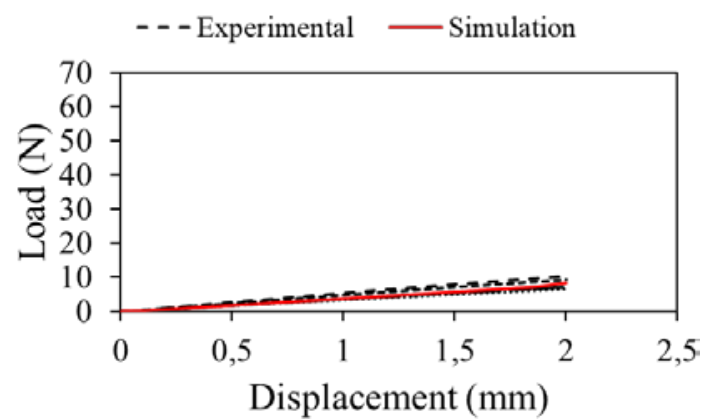

(a)

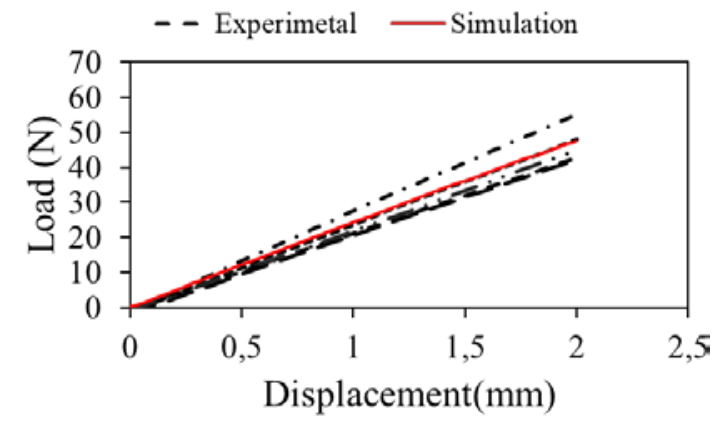

(b)

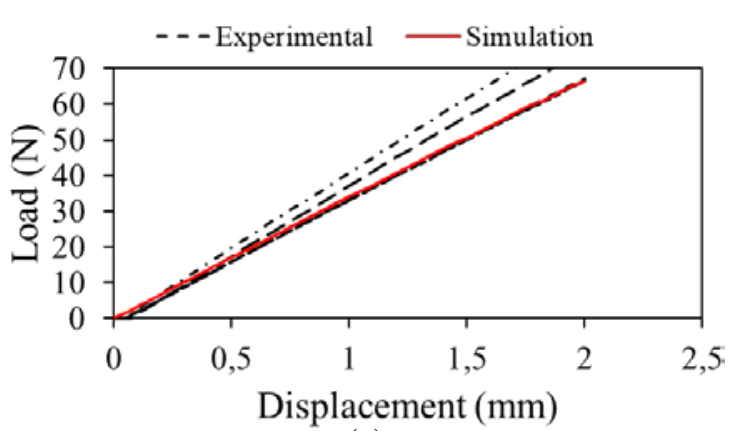

(c)

Figure 6: Load x Displacement diagram of flexural tests by experimental and numerical simulation: (a) Polymer Epoxy, (b) PE3L and (c) PE5L

\subsection{Analytical Method}

The results of the Analytical Method, Experimental average and Numerical Simulation are shown in Table 3. Considering maximum displacement of $2 \mathrm{~mm}$, observed values of loading and normal stress in the specimens. With respect to the force values, it can be noted that the results of the non-linear simulations are closer to the experimental results. 
However, the results of the linear simulations were closer to the analytical results, probably because these two methods have the same simplifications (used to small deformations and to disregard the contact conditions). The tensile stresses on the faces of the laminate showed similar results among the three methods. Compression stresses were not analysed due to the influence of the rigid elements in the linear simulation results. Observing the epoxy resin, the nonlinear simulation results were slightly closer to the analytical results.

Table 3: Experimental, Numerical Simulation and Analytical results.

\begin{tabular}{|c|c|c|c|c|}
\hline Methods & Experimental & $\begin{array}{c}\text { Linear } \\
\text { Simulation }\end{array}$ & $\begin{array}{c}\text { Non-Linear } \\
\text { Simulation }\end{array}$ & $\begin{array}{c}\text { Analytical } \\
\text { Method }\end{array}$ \\
\hline \multicolumn{5}{|c|}{ Polymer Epoxy } \\
\hline Load [N] & 7.97 & 6.85 & 8.20 & 6.75 \\
\hline $\begin{array}{c}\text { Max Stress } \\
\text { Faces[MPa] }\end{array}$ & - & - & - & - \\
\hline $\begin{array}{c}\text { Max Stress } \\
\text { Epoxy [MPa] }\end{array}$ & - & 8.60 & 9.50 & 9.00 \\
\hline \multicolumn{5}{|c|}{ PE3L } \\
\hline Load [N] & 46.63 & 49.80 & 47.50 & 49.50 \\
\hline $\begin{array}{c}\text { Max Stress } \\
\text { Faces[MPa] }\end{array}$ & - & 86.70 & 85.90 & 90.00 \\
\hline $\begin{array}{c}\text { Max Stress } \\
\text { Epoxy [MPa] }\end{array}$ & - & 5.00 & 4.00 & 3.60 \\
\hline \multicolumn{5}{|c|}{ PE5L } \\
\hline Load [N] & 69.80 & 63.90 & 64.00 & 63.60 \\
\hline $\begin{array}{c}\text { Max Stress } \\
\text { Faces[MPa] }\end{array}$ & - & 86.70 & 85.80 & 90.00 \\
\hline $\begin{array}{c}\text { Max Stress } \\
\text { Epoxy [MPa] }\end{array}$ & - & 4.00 & 3.00 & 3.00 \\
\hline
\end{tabular}

\section{CONCLUSIONS}

In this paper, it was evaluated the behavior in three-point bending of polymer epoxy reinforced with glass fiber laminated faces through four different methods. The values of load, displacement and stress were obtained and compared. It was possible to observe that, despite the considerably lower computational cost, linear simulation should be used with caution because the small displacements limitations and rigid elements influence, mainly in compress stress. Non-linear dynamic analysis with contact simulation has a higher computational cost, however the results can be more reliable.

\section{ACKNOWLEDGEMENTS}

The authors thank to FAPEMIG, CAPES and CNPq for the support in this paper. 
$4^{\text {th }}$ Brazilian Conference on Composite Materials. Rio de Janeiro, July $22^{\text {nd }}-25^{\text {th }}$, 2018

\section{REFERENCES}

[1] Felipe, R.C., Felipe, R. N., Melo, A.C., Batista, C., Aquino, E.M. 'Polymer Composites Reinforced with Hybrid Fiber Fabrics', Materials Research, 20 (2) (2017) 555-567.

[2] Tamilarasan, U., Karunamoorthy, L., Palanikumar, K., 'Mechanical Properties Evaluation of the Carbon Fibre Reinforced Aluminium Sandwich Composites', Materials Research, 18 (5) (2015) 1029-1037.

[3] Zenkert, D., Industrifond, N., 'The Handbook of Sandwich Construction’, Emas publishing; 1997.

[4] Levy Neto, F., Pardini, L.C. 'Compósitos Estruturais: Ciência e Tecnologia', (Edgard, Blücher, 2006).

[5] Daniel, I.M., Ishai, O., 'Engineering mechanics of composite materials', (Oxford University Press, New York, 1994).

[6] Santos, J.C., Vieira, L.M., Panzera, T.H., Shiavon, M.A., Christoforo, A.L, Scarpa, F., 'Hybrid glass fibre reinforced composites with micro and poly-diallyldimethylammonium chloride (PDDA) functionalized nano sílica inclusions.' Materials and Design: 65 (2015) 543-549.

[7] Chemami, A., Bey, K., Gilgert, J., Azari, Z., 'Behaviour of composite sandwich foam-laminated glass/epoxy under solicitation static and fatigue’, Composites Part B: Engineering, 43 (3) (2012) 1178-1184.

[8] Borrego L.P., Costa J.D.M., Ferreira J.A.M., Silva H., 'Fatigue behaviour of glass fibre reinforced epoxy composites enhanced with nanoparticles’, Composites Part B Engineering, 62, (2014) 6572.

[9] Bey, K., Tadjine, K., Khelif, R., Chemami A., Benamira, M., Azari, Z., 'Mechanical Behavior of Sandwich Composites Under Three-Point Bending Fatigue. Mechanics of Composite Materials', 50 (6) (2015) 747-756.

[10]Mantari, J.I., Soares, C.G., 'Generalized layer wise HSDT and finite element formulation for symmetric laminated and sandwich composite plates. Composite Structures’, 105 (2013) 319-331.

[11]Cheloni, J.P.M., Silveira, M.E., 'Analytical and numerical analysis of laminated composite tubes. Brazilian Conference on Composite Materials' Proceedings of Brazilian Conference on Composite Materials-BCCM3, 2016 Aug 28-31 Gramado, RS Brazil.

[12]American Society for Testing and Materials. ASTM D3039-14. 'Standard Test Method for Tensile Properties of Polymer Matrix Composite Materials', 2014.

[13]American Society for Testing and Materials. ASTM D638-14. 'Standard Test Method for Tensile Properties of Plastics', 2014.

[14]British Standards Institution BS 2562: 1997; 'Carbon fibre reinforced plastics-Unidectional laminates-Flexural test parallel to the fibre direction’, London, 1997. 